\title{
What kind of pen do I need to use to write my culture and my language?
}

\author{
SATORU NAKAGAWA
}

University of Alberta

\begin{abstract}
Through a form of narrative inquiry involving the use of vignettes and ruminations about present and past, the author examines the role(s) of orality, literacy, and aurality in the intergenerational transmission of his language and culture. Weaving together stories from childhood, memories, and translations of his grandmother's poetry, the author raises questions about how we, as Indigenous peoples, might ensure that we are able to teach our own next generations our spirits, hearts, being/knowing of the world and who we are as human beings now that oral cultures are being discarded--or worse, written down.
\end{abstract}

Because he died in the war

Rank and medals were provided

Formality, and the coldness of texts.

Yoshi Nakagawa

My four sons lived beyond World War Two.

Each has now surpassed their father's age of death, And is working hard.

Yoshi Nakagawa

(translated by Satoru Nakagawa)

\section{Introduction}

In this paper, I reflect on the relationships between thought and oral language, thought and written language, ruminating on what it is that written language has done.... and what it has undone. Havelock (1986) argued that the act of writing made available different forms of thinking and organization than were available in pre-literate 
times, and that therefore literacy has shaped the structure of human thought. In this paper, I explore the multiple layers of some of the questions posed by Havelock (1986) with reference to my own family experiences of oral and written memories, passed to me from my parents and grandmothers. Whereas Havelock (1986) asked: "What has it meant for societies and their cultures in the past to discard oral means of communication in favor of literate ones of various sorts?... What precisely is the relationship between the spoken word of today (or yesterday) and the written text?" (p. 24), I reframed these questions so that I can think about them from a personal perspective: "What does it mean for me (and my family) to be caught between an oral and a written culture?"

To do so, I will take a considerable risk. I will tell stories and relate vignettes about real people, people to whom I belong and who belong to me. I will share my thinking about each of these stories and vignettes with you. I have written in short sentences with few citations, as I intend this paper to be read aloud. Smith (1999) reminds us, "academic writing is a form of selecting, arranging and presenting knowledge. It privileges sets of texts, views about the history of an idea, what issues count as significant, and, by engaging the same process uncritically, we too can render indigenous writers invisible or unimportant while reinforcing the validity of other writers" (p. 36), or in my words "using units which are legitimated by the dominant society/culture" (Nakagawa, 2008, p. 26). I cite Smith's work, aware of the irony of doing so to legitimate my reasons for not engaging in standard academic writing practices.

I am a product of an oral language that has no name, but which is sometimes referred to as shimaguchi (island mouth). Some scholars would call us Indigenous ${ }^{1}$. As a child at school I developed literacy in a dominant language, Japanese, and then, as an adult, I developed literacy in the ultimate dominator language, what has been referred to as a murderous language (e.g., Skutnabb-Kangas, 2000), the language which "trumps" other languages (Nakagawa \& Kouritzin, 2011), English. As a parent now myself, the father of (dominant) Japanese and (dominator) English speaking children, the most important question for me is whether and how it is possible to pass on my truth, my culture, my beliefs, my wisdom, and my essence to my children, when they do not speak my heart's language. How can I pass on what I know in an oral language that is being lost? Can my

\footnotetext{
1 While the term "Indigenous" may be applied to the islanders of Tokunoshima, this description would not please us. Moreover, it is a term used by dominant societies, not by people who live in harmony with Mother Nature and themselves.
} 
children hear/feel my heart's memory?

\section{Yoshi Nakagawa's $100^{\text {th }}$ birthday}

Around the time of what many Western people think of as Christmas in 2006, my grandmother Yoshi Nakagawa had her $100^{\text {th }}$ birthday party, a celebration which is more like a ceremony. She was born in 1906 on the island of Tokunoshima, Japan. We all think she was born in 1906, but no one really knows exactly when she was born--just like anyone else on the island born back then. At the time she was born, the people on the island did not have to record their children into the family register system so that they would have an official identity. My grandmother Yoshi had an identity that was not recorded until long after her birth. Presently on our island, if a child's identity is not recorded in the public system at birth, that child could lose something in the education system, meaning that it is possible that the child might enter the school system later than his/her peer group —or worse, the child might not enter at all, or even officially exist.

When Yoshi Nakagawa went to school, the writing systems were reserved mainly for people with higher society rank who were educated in the mainland Japanese education system; this education was not readily available to regular citizens on the island. In fact, even today according to mainland Japanese people, we island people are nothing but peasants, or primitives, or country people; we are not regular citizens at all. Nonetheless, my grandmother was educated, and therefore she wrote poetry in standard Japanese.

According to her own writing (Y. Nakagawa, 1985), my grandmother Yoshi was born into a family of means because her father owned a business. As a result, she was able to obtain higher educational achievement and credentials in comparison to the times and lifestyles of other islanders. In school, she learned to read and write Japanese "Haiku," the superior poetry writing style of traditional culture in Mainland Japan. My grandmother Yoshi wrote a lot of poetry.

When she was in her early twenties, Yoshi was married to my grandfather, Yoshinori Nakagawa, who was a public school teacher and sugar cane farmer, and they soon had six children. At that time, she stopped practicing writing Haiku. She had a difficult life looking after her large family. They lived on subsistence farming. During World War II, Yoshinori Nakagawa was killed, leaving my grandmother and six young children behind. In a country still at war, with so few resources, Yoshi Nakagawa had to send her very young children to the mainland of Japan, alone on a ferry through 
torpedo-infested waters, trusting that someone would care for them and feed them there. In my father's case, he left the island while still extremely young. He lived with extended family, but did not have the advantages of having a mother and father, the love, the compassion, the tenderness that comes with living with parents. In a starving nation, he remembers searching the streets for food, like many others. The island where Yoshi Nakagawa lived was occupied by the Japanese, and then by the Americans. It was not until they were young adults that her children were able to return to the island.

When Yoshi was around the age of 60, when her children were grown and settled, she started to write haiku again. From that time until the late 1990s, she actively produced and published her poetry. Over the years, Yoshi Nakagawa developed a rapidly progressing form of pre-senile dementia, then dementia, and she came under the care of my father, her third son. Unfortunately, her declining health taxed both of my parents' abilities to take care of her, especially as their own ages increased. Yoshi, eventually, was placed into a medical care home, where she has been living since shortly after her $100^{\text {th }}$ birthday. Early in February 2007, she had a stroke and is now bedridden, suffering from lack of mobility and loss of her language. I am able to write about her now because she was able to record her work and her life in writing during extended periods in her life.

\section{Yoshi Nakagawa's books}

Yoshi Nakagawa left a large amount of her work in writing. My father gave me her books when I was a young man. I looked at them and said to myself "they seem interesting but not interesting enough to sit down and actually read them just now." In the back of my mind, I probably had the thought that her books were just about her life, that I would not understand them. Indeed, I did not understand them, perhaps because I was not particularly interested in the past. Over the intervening years, I have been pulling her books out and I have looked through them mindlessly. But, really, I did not understand the complicated old-fashioned Japanese characters and expressions that kept me from fully understanding what she was really trying to say. Simply, my Japanese was not sophisticated enough to read my grandmother's haiku, and that, coupled with my lack of life experiences made her writing incomprehensible to me. But, now when I look at her books, I see many layers in her thoughts: joy, sorrow, anger, wishes, and many other feelings throughout her long life on Tokunoshima, and the loss of her husband in WWII.

In many places in her books, where her life overlaps with my life, sometimes I can 
hear her voice speaking her culture to me in her language - but not ever in the written language of Japanese, even though books are written in standard Japanese. I can hear her voice in her language (Tokunoshima language: Shimaguchi); I can see her life in her house (which no one lives in anymore, and which Nature has started to reclaim as part of herself); in those moments, I can feel her life.

While I was growing up, I often stayed at my grandmother Yoshi's house with many of my cousins. I still remember the nights and mornings. I remember the chaos and excitement of my grandmother Yoshi's house when we were all there, when we all visited twice a year during "obon" (the festival when our ancestors' spirits returned to our homes) and "oshogatsu" (the three day celebration of the new year). I remember how she laid down the rules without exactly saying to us what they were. The rules came down gently though different generations, and through the older children to the younger ones like us.

When I became a teenager, I had "enough" knowledge to choose not to participate in such family activities. I preferred to stay in bed, rather than be dragged around the island by my parents to see my relatives and family. Since that time, I have been somewhat absent from my family, spirits, and culture. And yet, after all these years of my absence from my culture and from the essence of my being, I can still hear my grandmother talk, act, feel, and live in her books. I see her live; I feel her movements; I hear her language speaking to me from the pages of her book because of the time I spent with her. When I read her books, I know she is still there with me, and living her life the way I remember it. She is "there"-and I can feel that "there" is somewhere. My grandmother Yoshi is still on that island in that time with me, and all our family members who were there are all still with me, and in her books we are still all there. But "there" is not in her books. "There" is a place in oral time and space. "There" is not a written space. While Grandmother Yoshi's books are written in standard Japanese, I do not hear a word of standard Japanese from her books. I hear only her voice in Tokunoshima language, shimaguchi, speaking to me from the pages when I read. I wonder why?

\section{Language and culture in me}

Peoples and cultures have their own lifestyles and, accordingly, their lifestyles come with their own "truths" in life and their own "justices" emanating from those truths. Cultures have their own ways to understand the world and to express their knowledges and understandings through their languages. I grew up with a people and a culture in 
Tokunoshima, Japan. My languages were Shimaguchi (Tokunoshima language) and standard (school) Japanese. Although some people may consider me to be a speaker of shimaguchi, I do not have complete ease and fluency in my own Shimaguchi language. I understand almost all of the time when it is spoken to me, but when I want to express myself, the words do not come to my tongue and lips automatically to create the sounds that I want to convey, nor to express the thoughts that I hoped for in my heart.

Whether I like it or not, my first language is Japanese but my first culture is Tokunoshima culture. This mismatch in my language and culture is very strange for me. I understand the Japanese language better, but I live in the Tokunoshima culture. I have taken advantage of speaking the dominant (Japanese) language on many occasions, and I have at times used the Japanese language against my own cultural beliefs and people, such as when I did my teaching practicum at a Tokunoshima high school and had to lecture in standard Japanese about concepts that have no bearing on our island being. Consequently, when I see many cultural aspects of expression in Tokunoshima, especially the ceremonial aspects, some really "speak" to me, but others have no meaning. I do not mean that I devalue their intent or their appearance, but rather that I simply have no idea what people are trying to "say." There is only one thing I know for sure — whatever they are saying is important. People are saying something that is important for them to say, and they would like the "other," the listener, to be someone who is willing to understand them through their different forms of expressions and values. Knowing this, I realize that ceremonial aspects of communication from other cultures, expressed through oral mediums like dance, performance, music, ritual, are important, even when I do not know what they mean.

\section{An eight year old's perspective}

I showed some cultural ceremonial and symbolic pictures from other cultures, representations of communications that are not written, to my son when he was eight years old. Many of the pictures he understood, and some he was even able to explain, such as Japanese tea ceremony (he did not say too much but he recognized the picture was from Japan), a European style wedding, and graduation pictures. When he was shown a picture of a North American Aboriginal dance he did not ask any questions, though he was concerned about a turtle shell in the picture, wanting to know if the turtle was killed for the ceremonial purposes or not. Then, when he saw another picture that was labeled "Aborigine" from somewhere in the Southern Pacific Ocean region, he asked me what the 
picture was, and noted that it was "scary." The picture of a South Pacific Aborigine in ceremonial paint was totally foreign to him and he simply had no way to comprehend the picture. He had not been exposed to any of the cultures (or even pictures of the cultures) of the Southern Pacific Ocean; although he did not understand that the ceremonial paint was intended to make them look fierce, he did find them frightening. In spite of my efforts to then teach him the differences between the European-based ceremonies and other familiar ceremonies in multiple cultural backgrounds, my son was unable to see the similarities among the other cultures' intentions. He was concerned with what the people were wearing, and what the "pictures they had on their skin" (paint or tattoos) represented to them. At the age of eight, he had already learned to distinguish between the cultures of his experience and familiarity, and cultures of the "strange." As a parent, I have to continue to ask him--and myself--what are differences among the different cultures' ceremonial intentions, wills, desires, and drives?

\section{Green grass and green light (or blue grass and blue light)}

I am not unlike my son. I cannot always separate the familiar and the unfamiliar. Coming to Canada, I saw traffic lights, trees, and field grasses as being blue. After arriving in Canada and speaking to many people, I came to realize that both the traffic lights and all forms of grass are spoken of as green. I am not colourblind; I just see the world differently than many Canadians do.

In Japan through the medium of Japanese, where I learned the basics of my language, values, truth, and all other aspects of life, the colour blue (specifically indigo) is a metaphor for liveliness. We say traffic lights are blue, and trees and grasses are blue, with the aspect of liveliness as the connotation in our expressions. In opposition to the Japanese connotation, in English, the color "blue" seems to express images that represent sickness, low-down feelings, depression, and oppressive meanings, as in phrases like "feeling blue," "out of the blue," " the Blues" (music), and "blue collar." However, in Canada, as far as I can see, traffic lights, trees, and grasses are "green". I know intellectually they are green, but green does not provide the connotation of liveliness to me. To understand the matter of color as a fact is easy, but we need to have our values attached to the words; our values can only be read or understood in the way they were meant through human interaction and integration. It seems to me that I am living in one set of colors but in multi-layers of meaning. I am often required to stop and to think about what I am saying and hearing, as 
well as what I am reading and writing. Even though each language that I use provides different connotations, and even different nuances to those connotations, within specific situations and environments, I find I am able to use and understand the words correctly in each context. I have wondered for a long time, "Why is that?" What is the nature of the relationship between words when one speaks more than one language? Does everyone use the words correctly, but feel differently? It stands to reason "yes", and not only between cultures, but within them as well.

\section{Orality and written text: As aurality (listening) and reading text}

Thinking through my grandmother's books, I have come up with a question, a simple question. That is, if I am reading my grandmother's life and her ideas in standard Japanese, why I am hearing my grandmother's voice, and more importantly, why do I hear her voice in Tokunoshima language? When I close my eyes, I imagine her talking to me through the ideas she put it in the written language, but I hear her voice in her language, more particularly, in the way she used to talk to me. I wondered if this happened to my parents, who spent more time with my grandmother, as well. So, I telephoned my parents in Japan just to ask this question. Their answer was as I expected; my parents--who used to live under the same roof with my grandmother Yoshi--also hear my grandmother's voice when they close their eyes, and they imagine her in her own house when she wrote these haiku when they read her poetry. They were surprised that I would telephone with such a question. That was a kind of dumb question for me to be asking, they thought, especially since they knew I would have no memories of my parents and my grandmother speaking in standard Japanese. Of course, my parents and my grandmother NEVER spoke standard Japanese together. I wonder if my parents even have a memory of speaking to each other in standard Japanese, perhaps on some formal public occasion? Perhaps in front of me? Perhaps in "polite" company?

As a result, I question whether there is a simple model of the relationship between

aurality and reading written text. When I hear a voice and when I read the text--what is the difference? Could it really be as simple as Ong (2002) notes about reader response theory:

...writing and reading differ from oral communication, and in terms of absence: the reader is normally absent when the writer writes and the writer is normally absent when the reader reads, whereas in oral communication speaker and hearer are present to one another. (p. 167) 
It seems more complicated than that. I am thinking about this in terms of the two different language systems and cultures. Both my parents' and my own experiences of hearing my grandmother's voice implies that we are simply experiencing the oral language and culture of my grandmother as told to us through the medium of a different system, a writing system. And, of course I wonder, if my children read these words that I am writing now, will they "hear" my voice in Japanese speaking to them, because I have never spoken English to them?

In the animal kingdom, living creatures (in particular, birds and primates) use communication systems to exchange vital information within their communities (e.g., Dunber, 2004; Sinha, 2004). Most of the research does not yet specify the reasons behind the communication, or why or how various members of the animal kingdom understand each other's vocalizations, but the researchers are clear that implicit in their sounds is the intention of communication. As we all know, animals often have self-defense-oriented communication systems; for example, one ant's death will release pheromones so that all other ants will panic and run for their lives; dogs will bark at strangers to let their owners know there are intruders on their premises; one bee will bring thousands of additional bees to a task by dancing in its hive. Not all forms of communication involve sound. Understanding, even recognizing, such communication systems in the animal kingdom should bring humans to the point of realizing the importance and accuracy of oral communication systems (including performance), especially since no living creatures other than humans use writing systems to communicate. It seems clear that oral communication can be very precise and accurate when communication systems contain vital information essential to survival.

Oral communication is precise for human learning too. When children begin to learn, they are not initially taught through writing systems how to recognize what their elders value in life, or how to behave. We all learn "the basics" of our lives and languages before entering the school system, which means before learning the writing system. We are generally more willing to tell the truth orally; the English phrase "off the record" reminds us that oral language has a connection to truth speaking, while writing is for legal purposes, for show, for sham, for evidence.

What kind of pen do I use to write my culture for my children? I came to Canada when I was 24 years old, nearly 19 years ago. I did not speak 
much English then. I was able to have conversations with people about daily needs and the most basic necessities of life. Over time, I learned enough English to enable me to enter university graduate education in Canada. Meanwhile, I became a father of two children, a girl who became fluent in speaking in both Japanese and English and a boy who became almost fluent aurally in conversational Japanese and completely fluent in English. (I should note that my son suffers from Stevens Johnsons Syndrome, and that an acute episode left him without language for the first four and a half years of his life). My wife and I have been busy speaking to our children in Japanese, creating a Japanese language environment through videos and DVDs and our own conversations, to teach orality in Japanese. We anticipated that their mother's English orality would eventually be taught by the society through our children's socialization with their peer groups. This was a strategic move by us as parents; we were counting on social hegemony (Gramsci, 1971) for our children to gain English, and we were ensuring that they would also learn Japanese.

The unfortunate consequence of living in Canada was that my children lost the chance to grow up with the Tokunoshima language. For my children to use and speak Shimaguchi, they first needed me to speak the language, followed by having a language community that would force them to use the language in real life contexts. Neither possibility was available to my children. I was barely able to teach my children what it means to be Japanese through speaking to them and watching Japanese videos and movies. I was continuously involved in interactions with them about the on-screen images. I had to quit work and delay going to school to provide continuous Japanese input to them at home. Until my children began school, I had to give up my own life in order to make sure that they were surrounded by the Japanese language all day, everyday. But, by doing so, I was able to raise them to understand, at least, my spirit and soul in Japanese.

It is very sad to admit that although my wife's and my tactics worked in teaching standard Japanese to our children, I totally failed to teach them my island language. They can only learn it orally. To this day, my island does not have a writing system; we can borrow from the Japanese writing system to express our language in text, but according to my mother, and based on my own experience, I know that it is impossible to read and thereby understand the meaning of our language. We do not have conversations through writing systems, nor do we have the habit of writing conversations down on pieces of paper. The consciousness of writing on paper was not developed until recently, and unless there are strong forces insisting that we do so, Tokunoshima language users will never immerse 
themselves in language as writing/reading material. Simply put, island language will not accept any writing system.

I had great experiences throughout my life with my island and my culture, despite interference from the dominant force of the Japanese system imposed on us. Japanese changed my own life so that it is completely different from my parents' and grandparents' ways of life. Yet, I was able to spend vast quantities of time with my parents and grandparents. Now it is my turn to provide the same to my children. I am somehow stuck in a gap between my parents' generation of islanders and my generation of islanders after living through both the hegemony of the Japanese education system as a credential-earning process, and then again living between Canadian culture and language (in this case English) with Asian culture and language (Japanese). Without Japanese, I did not have sufficient resources in terms of people around me or my own language skill to teach my children the way I understand the world through my island language. I am hoping my children have learned, and that they are/will be able to extrapolate from their knowledge of Japanese and their knowledge of me, to understand where and how and who I am, my Being and knowing within my own world view. I hope they can see through the artifice of the Japanese language and the English language so that I am visible somewhere, a Shimaguchi speaker who is mute.

By reviewing my life and my choices as reflected in my children, I now have to reflect on the same idea with regard to language and culture on the island itself. My generation is now the parenting generation and we are not using the language and culture to teach our children, not even on the island, simply because, for the most part, our generation does not have sufficient language skill to teach the next generations. And, in my own family, we live across/within/between three languages: Shimaguchi, Japanese, and English. I am haunted by wondering about the message being sent to me by my grandmother's books--should we write in standard Japanese to tell the stories of our lives and values to our children and our children's children, or should we borrow the Japanese writing system to express ourselves in Shimaguchi, or should we not write? Is all written history a momentary blip in oral time? Whatever choices we make, we must ensure that we are able to teach the generation after us about our spirits, hearts, being/knowing of the world and who we are. But, we need also ask ourselves if we should strive to teach beyond the next generation - or if that is the next generation's right and responsibility. Is it arrogance for us to want to reach people living in the future beyond living memories of us just because we have pen and ink? 
Or should we not ask for immortality in that way? So I ask myself: "What kind of pen do I need to use to write my language and to write my culture in order to ensure that my teachings remain relevant and truthful and do not remain in a form that would corrupt future generations?" Maybe I/we should use a pencil so that I/we can erase and change. Maybe I/we should use disappearing ink.

\section{References}

Dunber R. I. M. (2004). Language, music, and laughter in evolutionary perspective. In Kimbrough \& Griebel (Eds.), Evolution of communication systems: A comparative approach (pp. 257-273). London, England: The MIT Press.

Gramsci, A. (1971 [1927]). On Education. Selections from Prison Notebooks._New York: International.

Havelock, E. A. (1986). The muse learns to write: Reflections on orality and literacy from antiquity to the present. New Haven: Yale University Press.

Nakagawa, S. (2008). Information and wisdom in the practice of knowledge. Journal of contemporary issues in education, 3(2), 24-45.

Nakagawa, S. \& Kouritzin, S. (2011). Present tense[ions] of English in one local context in Japan. Critical Inquiry in Language Studies, 8(1) 53-71.

Nakagawa, Y. (1985). Saigetsu. [Time]. Tokyo, Japan: Ima-Shobou.

Ong, W. J. (2002). Orality and Literacy. New York: Routledge.

Sinha, C. (2004). The evolution of language: From signals to symbols to system. In Kimbrough \& Griebel (Eds.), Evolution of communication systems: A comparative approach (pp. 217-235). London, England: The MIT Press.

Smith, L. T. (1999). Decolonizing methodologies: Research and Indigenous peoples. New York, NY: Zed Books.

\section{Author biography}

Satoru Nakagawa is a Ph.D. candidate in Educational Policy Studies specializing in Indigenous People's Education at the University of Alberta. 